\title{
Design considerations for a continuous emission measurement system for pressure type bag houses
}

\author{
Pierru Roberts ${ }^{1}$, Luther Els ${ }^{1}$ and Gerrit Kornelius ${ }^{1,2}$ \\ ${ }^{1}$ Resonant Environmental Technologies, Centurion, 0046, pierru@resonant.co.za, luther@resonant.co,za \\ 2 Department of Chemical Engineering, University of Pretoria, Pretoria, 0002, gerrit.kornelius@up.ac.za
}

\begin{abstract}
Measurement of the outlet particulate concentration on pressure-type bag filters, whether intermittent or continuous, has been avoided in South Africa as cumbersome and possibly inaccurate. A system based on the requirements of the US EPA's method 5D was however recently designed and installed on three pressure-type reverse air filters serving ferro-chrome electric arc furnaces in order to allow comparison with the legal emission concentration limits for this type of furnace. This paper reports on the design considerations and design process of this system.
\end{abstract}

Keywords

continuous sampling, pressure bag house, particulate matter

\section{Introduction}

Fabric filters are one of the most widely used devices for controlling emissions of particulate matter (PM). A fabric filter system typically consists of multiple filter elements, or bags, enclosed in a compartment, or housing. The process stream enters the housing and passes through the filter elements. Particulate matter (PM) accumulates as a dust cake on the surface of the bag. This dust layer effectively becomes the filtration medium. The filter elements are cleaned periodically to remove the collected dust (Cooper and Alley 2012).

Fabric filters generally are classified by cleaning method. The four types of cleaning method are reverse-air, shaker, pulsejet, and sonic cleaning. Fabric filters can also be classified as either positive- or negative-pressure designs, depending upon the location of the fan(s) that provides the motive force for the exhaust stream through the unit. The fan is located upstream of the filter in a positive-pressure (forced-draft) unit, and downstream of the filter housing in a negative-pressure (induced-draft) unit.

Upstream location of the fan means that no duct work or exhaust stack is required on the outlet or downstream side. In fact, the gas after cleaning often exits the filter installation through openings similar to those used for roof ventilation in industrial buildings (called mono-vents). The customary measuring techniques for PM emissions cannot be used in this case, as there is no suitable measuring location that conforms to the flow conditions as required by the frequently used methods EPA 5A or ISO 9096, which are also the methods allowed by Schedule A of the s21 regulations under the South African Air Quality Act (Department of Environmental Affairs 2010, 2013).

\section{Application description}

Middelburg Ferrochrome (MFC), a subsidiary of Samancor Chrome, has three pressure-type reverse air bag filter installations serving their electric arc furnaces. MFC has taken the positive step of specifying a continuous emission sampling system. This enables them to not only report an annual emission result but also to continuously monitor their emissions in order to reduce emissions and the overall environmental impact.

\section{Emission monitoring requirements}

Fabric filters are capable of extremely high control efficiencies of both coarse and fine particles; outlet concentrations as low as $20-30 \mathrm{mg} / \mathrm{Nm}^{3}$ with conventional bags and emissions as low as $10 \mathrm{mg} / \mathrm{Nm}^{3}$ with membrane bags can be achieved. (Roberts et al 2013).

The South African emission limits as set out by the Department of Environmental Affairs $(2010,2013)$ in terms of regulations published under 21 of the National Environmental Management - Air Quality Act for an open furnace producing ferrochrome are given in Table 1.

Table 1: Emission limits - Ferro-alloy production

\begin{tabular}{|l|l|l|}
\hline Common name & Plant status & $\mathbf{m g} / \mathbf{N m}^{\mathbf{3}}$ \\
\hline \multirow{2}{*}{ Sulphur dioxide } & New & 500 \\
\cline { 2 - 3 } & Existing & 500 \\
\hline \multirow{2}{*}{ Oxides of Nitrogen } & New & 400 \\
\cline { 2 - 3 } & Existing & 750 \\
\hline \multirow{2}{*}{ Particular matter } & New & 30 \\
\hline & Existing & 100 \\
\hline
\end{tabular}

* Under normal conditions of $273 \mathrm{~K}$ and $101.3 \mathrm{kPa}$ 
Continuous emission monitoring (CEM) for particulate concentration is not currently a national requirement for ferroalloy manufacturing under the above regulations. The local licensing authority has however specified continuous emission monitoring as a condition in the Atmospheric Emission License $(A E L)$ issued to this specific installation.

CEM is gaining favour among major industry players and is increasingly added as a company policy decision to improve monitoring and reporting capability.

\section{Methodology}

The United States Environmental Protection Agency (EPA) method 5D (Federal Register 2000) specifies the identification of alternative locations and procedures for sampling the PM emissions from positive pressure fabric filters. The EPA methods as well as the international Standards Organisation (ISO) methods are both recognised according to the South African legislation for emission testing.

\section{Sampling locations}

The possible alternative measurement locations when an induct testing location is not available for peaked roof and ridge vent type fabric filters are:

- Sampling in multiple short stacks (if stacks are present), which do not meet the required location criteria for duct sampling.

- $\quad$ Sampling directly above the filter housing in the ventilator throat / roof mono-vent.

- Sampling direct from the compartment housing above the filter bags.

The second and third options are illustrated in Figure 1 below.

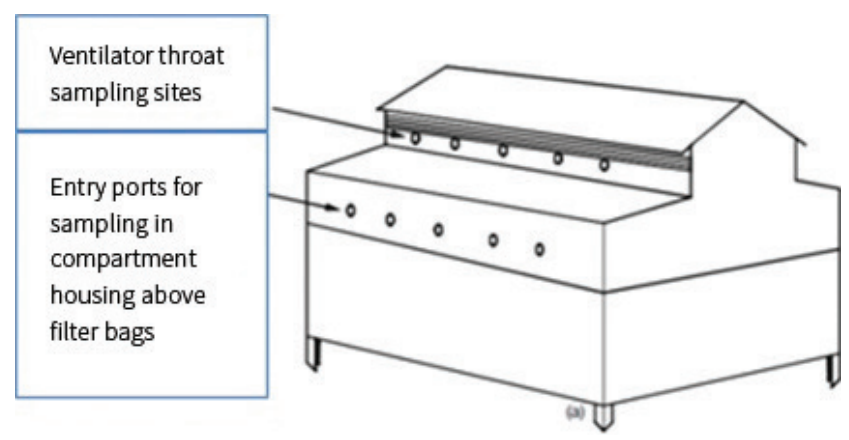

Figure 1: Acceptable sampling locations for peaked roof fabric filters (Federal Register 2000)

The alternative measurement locations need to be analysed according to structural suitability, measurement criteria and the choice between in-situ analysers versus an extraction system.

\section{Multiple short stacks not meeting the location criteria for duct sampling}

The filters at MFC have been designed with a mono-vent instead of multiple stacks to vent to atmosphere. It would however be possible to construct multiple stacks over the mono-vent to conform to the EPA specifications.

A structural audit will then have to be performed on the filter supports to determine whether the structure can support the weight associated with multiple roof stacks. Maintenance access to the analysers would also have to be added to the structural load on the roof.

The audit, design and installation cost would be considerable and would probably not justify the cost for purpose, i.e. to determine continuous emission concentrations. For that reason this was not considered as a feasible option in this instance.

\section{Roof mono-vent}

The mono-vent located on top of the bag filter is open to atmosphere at the top, with a bottom section at a slightly lower level. The continuous sampling system in the roof or monovent will have to conform to the following EPA 5D requirements (Federal Register 2000):

- Measurement should take place at the bottom of the mono-vent.

- The measurement should take place above any upstream exhaust point.

- A minimum of 24 traverse points.

The minimum of 24 traverse points will have to be dealt with by either extraction at these points or by individual analysers for in situ measurement at each of the points. The reduced cross-sectional area of the vent compared to the compartment outlet will increase the velocities and will thereby increase the accuracy of the measurement.

In situ measurements will however require additional maintenance access at each of the analysers. The structure of the roof will have to be analysed but should be able to bear the weight of one person. Additional grating will have to be added on the roof and fitted with railings.

\section{Compartment housing}

Using the compartment housings will structurally be the optimum solution. Minimal structural changes will have to be made to allow for sampling.

A continuous sampling system in the compartment housing will have to conform to the following EPA 5D (Federal Register 2000) requirements:

- $\quad$ Testing should take place directly above the filter bags.

- A minimum of eight points or equivalent should be measured on each of the testing sites.

- A minimum of $50 \%$ of the compartments needs to be sampled to obtain a representative sample.

- The sampling points need to be evenly distributed along the bag house.

In situ versus extraction system

Two options exist for measuring particulate matter concentration 
for the last two options described above. Measurements can either take place in situ meaning that analysers will be placed directly at each of the selected measurement location on the mono-vent, or by using an extractive system with a specified volume flow from each of the measurement points being sent to a separate combined measuring location.

\section{In situ measurement}

An in situ installation will require minimal structural changes to the bag filter housing. The large surface area of the bag filter outlet plenum and the limited range of the analysers will require a large number of analysers which will increase the installation as well as calibration and maintenance cost. In addition, the large number of analysers will each require an access point which will again increase the structural cost.

The expected velocity in the outlet of the bag compartments is in the order of $0.5 \mathrm{~m} / \mathrm{s}$ to $2 \mathrm{~m} / \mathrm{s}$. Electrodynamic analysers are not designed for such low velocities. In situ measurement using an electrodynamic instrument will therefore not be possible.

Installing a dynamic opacity measuring system according to the EPA recommended standards will require a minimum of 8 transmitters and receivers per bag house.

The mono-vent of the filter housing is open to atmosphere. This would allow gas at temperatures above $100^{\circ} \mathrm{C}$ to be in contact with the analyser controller that is normally rated to approximately $50^{\circ} \mathrm{C}$ ambient operating temperatures. Additional controller cooling will then be required on each of the analysers adding to the already high analyser costs.

The only advantage of in-situ measurements would be the possibility of more accurately locating leaking bags.

\section{Extraction system}

An extraction system will transport the dust laden gas to a secondary location away from the harsh conditions at the top of the bag house. Only one analyser will be required per filter housing and no maintenance platforms will have to be constructed. This will off-set some of the construction cost associated with the installation of the extraction points.

\section{Application}

A continuous extraction system extracting from the mono-vent has therefore been selected. This method uses small extraction hoods to sample the gas from a number of locations and then transports the collective sample to a secondary measuring location. A structural layout indicating the hood locations as well as the duct routing is shown in Figure 2 below.

The rate of sampling cannot be determined by simply measuring the hood face velocity, as the velocities are low and measurement is therefore less accurate (Federal Register 2000). The EPA recognises the pitfalls involved in accurately measuring the velocities when dealing with low velocities varying across the length of a mono-vent or filter housing and proposes an alternative calculation method.

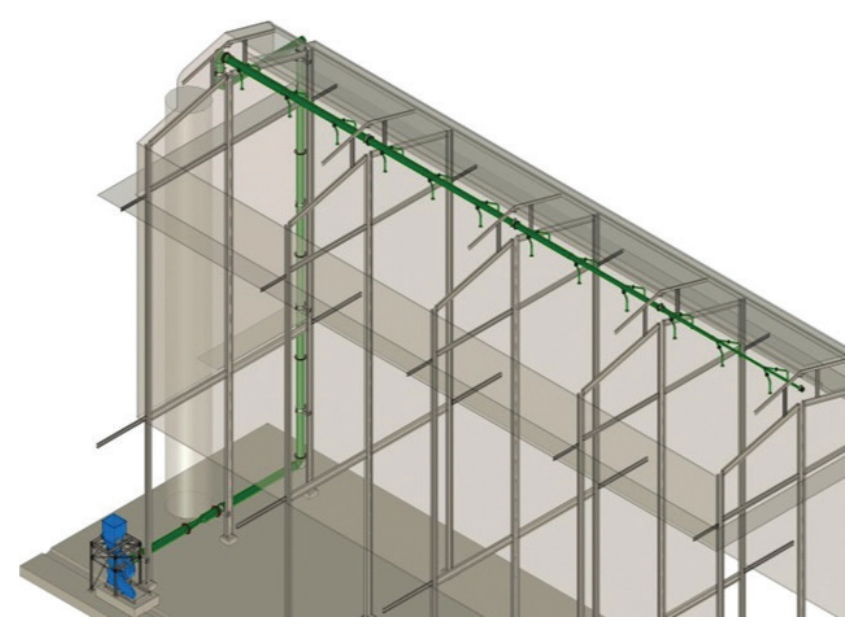

Figure 2: Structural layout

(Green: sampling ducting; Blue: Analyser location)

The prescribed calculation method is to measure the bag filter inlet volume (this would be measured for process reasons in any case) and calculate flow at the extraction points by using the temperature differences between the inlet and the sample extraction locations to adjust for dilution between the bags and the sampling location using a dilution factor. This is required because additional air is drawn in at the bottom of filter housing by the buoyancy of the hot outlet gas. The dilution factor is calculated according to Equation 1 (Federal Register 2000).

$$
Q_{D}=\frac{Q_{1}\left(T_{1}-T_{0}\right)}{T_{0}-T_{A M B}}
$$

Where

- $\mathrm{Q}_{\mathrm{D}}$ is the dilution air volumetric flow rate $\left(\mathrm{m}^{3} / \mathrm{s}\right)$

- $Q_{1}$ is the filter inlet flow rate of the gas $\left(\mathrm{m}^{3} / \mathrm{s}\right)$

- $\quad \mathrm{T}_{1}$ is the filter inlet gas temperature $\left({ }^{\circ} \mathrm{C}\right)$

- $\quad \mathrm{T}_{0}$ is the mono-vent outlet gas temperature $\left({ }^{\circ} \mathrm{C}\right)$

- $\mathrm{T}_{\mathrm{AMB}}$ is the ambient temperature $\left({ }^{\circ} \mathrm{C}\right)$

The gas flow rate at the fabric filter inlet is measured for process purposes and therefore known. The required average velocity at the sample extraction location can therefore be calculated and approximate isokinetic sampling rates maintained the measurement locations. An equal gas sampling rate at each of the sampling points is ensured by careful design of the diameter of the sampling header along its length, and could in principle be made adjustable by allowing for the installation of replicable orifices at each sampling point.

A process flow diagram illustrating the instrumentation required is shown in Figure 3 below.

A control system that includes volumetric measurements, thermocouples at three locations in the system as well as balancing orifice plates in each extraction line has been included into the design. 


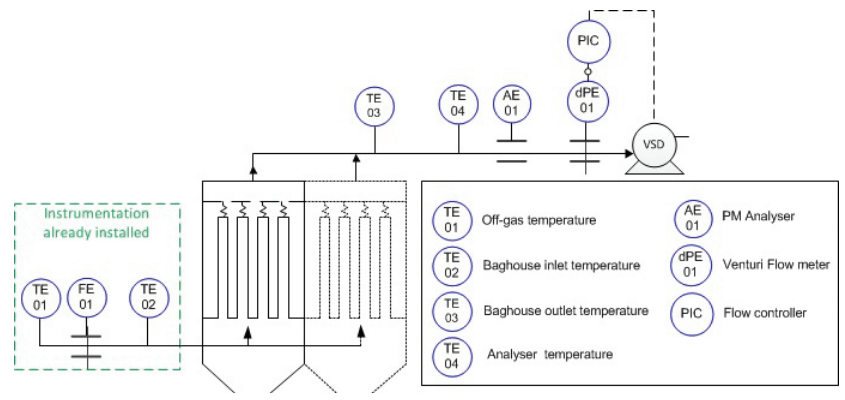

Figure 3: Process Flow Diagram

The sample flow will then be combined into a single duct and extracted with a fan. The electro-dynamic sampler was installed in the duct upstream of the extraction fan, together with suitable sampling ports for isokinetic testing to calibrate the instrument.

\section{Conclusion}

The following conclusions can be drawn from the continuous sampling design and installation project:

- Pressure-type reverse air bag houses do not conform to the laminar flow requirements normally required for accurate isokinetic sampling.

- The EPA method 5D prescribes alternative measurement locations and provides guidelines on the requirements of each of these locations.

- A solution for the specific application was designed.

\section{References}

Cooper, David C. \& Alley F. C. 2012, Air Pollution Control: A design Approach 4th ed. Waveland Press, Long Grove Ill.

Department of Environmental Affairs 2010 'List of activities which result in atmospheric emissions which have or may have a significant detrimental effect on the environment, including health, social conditions, economic conditions, ecological conditions or cultural heritage' Government Notice 248, Government Gazette 33064, 31 Mar 2010. Pretoria

Department of Environmental Affairs 2013 'List of activities which result in atmospheric emissions which have or may have a significant detrimental effect on the environment, including health, social conditions, economic conditions, ecological conditions or cultural heritage' Government Notice 893, Government Gazette 37054, 22 Nov 2013. Pretoria

Federal Register 2000 Volume 65 Issue 201 'Amendments for Testing and Monitoring Provisions' Pages 61744 - 62273. Washington, DC

Roberts P., Els L., Noakes S. and de Montard B. 2013 'Ferroalloy off-gas systems- from design to implementation and design verification process' Proceedings, INFACON XIII, International Ferro-Alloy Conference Almaty, Kazakhstan. 